\title{
The Effect Of Curvature Rate On The Received Power in the Parabolic Reflector
}

\author{
Amean S. Ghazi Ahmed A. Fadhel \\ College of Engineering - Thi-Qar university
}

\begin{abstract}
$\underline{\text { Abstract }}$
In this paper we study the effect of curvature rate on the generated electric field at the focus point if the frequency and diameter are constants. We assume that the incident electromagnetic waves distributed uniformly on each point of the reflector surface ;hence we can imagine that this reflector has uniform surface charge, and this body will generate an electric field on all points in front of it (including the focus point). This field can be obtained by using coulomb's law . The derived expression for electric field show that $\mathrm{X}$ and $\mathrm{Y}$ components will vanish and the electric field has a Z-component only (axis of symmetry).We draw the resultant electric field as a function of (F/D) ratio at constant antenna diameter. The obtained result showed that the electric field will increase as (F/D) ratio decrease, and decrease as (F/D) ratio increase if antenna diameter is constant .There is some fluctuations in the values of electric field when antenna diameter is small , and this fluctuations will decrease as antenna diameter increase at constant (F/D) ratio.
\end{abstract}




\section{Introduction:-}

Reflector antenna, in one or another form, have been in use since the discovery of electromagnetic wave propagation in 1888 by Hertz[1]. However the fine art of analyzing and designing reflectors of many various geometrical shapes did not forge ahead until the days of II World War when numerous radar applications evolved. Subsequent demand of reflectors for use in radio astronomy, microwave communication and satellite tracking resulted in spectacular progress in the development of sophisticated analytical and experimental techniques in shaping the reflector surfaces and optimizing illumination over their apertures so as to maximize the gain. The use of reflector antennas for deepspace communication, such as in the space program and especially their deployment on the surface of the moon, resulted in establishing the reflector antenna almost as a household word during the 1960s. Although reflector antennas take many geometrical configurations, some of the most popular shapes are the plane, corner, and curved reflectors (especially the paraboloid), as shown in Figure (1). Parabolic reflector is one of the famous form of reflector antenna. It has been shown by geometrical optics that if a beam of parallel rays is incident upon a reflector whose geometrical shape is a parabola, the radiation will converge (focus) at a spot which is known as the focal point .In the same manner if a point source is placed at a focal point the rays reflected by a parabolic reflector will emerge as parallel beam. This is one form of the principle of the reciprocity. The symmetrical point on the parabolic surface is known as the vertex the point in which the incident waves will emerge on it [1]-[3].There are different parameters which will effect on performance of parabolic reflector, one of these parameters is the curvature rates[4]. In this paper we study the effect of curvature rate on the received power in a parabolic reflector .

\section{Theory:-}

The simplest reflector antenna consist of two components :a reflector surface that is large relative to a wavelength and a much smaller feed antenna. The most popular form is the parabolic reflector shown in figure(2). The reflector or dish is a paraboloid of revolution. The intersection of the reflector with any plane containing the reflector axis(Z-axis) forms a curve of the parabolic type shown in fig(2). The equation describing the parabolic surface shape in the rectangular form using $\left(\rho^{\prime}, Z_{\mathrm{f}}\right)$ is [5]

$$
\left(\rho^{\prime}\right)^{2}=4 F\left(F-Z_{f}\right) \quad \rho^{\prime} \leq a
$$

The apex of the dish corresponds to $\rho^{\prime}=0$ and $Z_{f}=F$ and the edge of the dish is $\rho^{\prime}=a$ and $Z_{f}=F-\frac{a}{4 F}^{2}$. For a given displacement $\rho$ from the reflector axis ,the point

$\mathrm{R}$ on the reflector surface is $r_{f}$ distant away from the focal point . The parabolic curve can also be expressed in polar coordinate as [5]

$$
r_{f}=\frac{2 F}{1+\operatorname{CoS} \theta_{f}}=F \sec ^{2} \frac{\theta_{f}}{2}
$$

Then the projection of this distance $r_{f}$ onto the aperture plane is

$$
\rho^{\prime}=r_{f} \sin \theta_{f}=\frac{2 F \sin \theta_{f}}{1+\cos \theta_{f}}=2 F \tan \theta_{f}
$$


At the apex $\left(\theta_{f}=0\right), r_{f}=F$, and $\rho^{\prime}=0$, at the reflector edge $\left(\theta_{f}=\theta_{0}\right), r_{f}=\frac{2 F}{1+\cos \theta_{0}}$ and $\rho^{\prime}=a$. The axisymmetric parabolic reflector is completely specified with two parameters: the diameter D and the focal distance F. Equivalently, the reflector is often stated in terms of $\mathrm{D}$ and $\mathrm{F} / \mathrm{D}$ ratio, which give the size and shape(curvature rate) respectively[5]. If we increase the diameter $\mathrm{D}$ then the gain of the parabolic reflector increase as shown in figure (3).If we want to study the effect of curvature rate on the received power we can imagine the parabolic reflector as a surface charge with a surface charge density $\rho_{s}$. This charge will generate an electric field at all points in front off the reflector .To find the electric field at the focus point we use (coulomb's low)[7] :

$$
\vec{E}=\frac{Q}{4 \pi \varepsilon_{0} R^{2}} a_{R}
$$

Where $\mathrm{Q}$ is the total charge $\varepsilon_{0}$ is the relative permittivity, $\mathrm{R}$ is a vector from the radiating point to the focus point. Then

$$
d \vec{E}=\frac{d Q}{4 \pi \varepsilon_{0} R^{2}} a_{R}
$$

Any point on the paraboloid can be represent as $(\mathrm{X}, \mathrm{Y}, \mathrm{Z})$, while the focus point which is on the $\mathrm{Z}$-axis is $(0,0, \mathrm{~F})$, this make the vector $\mathrm{R}$ as follows:

$$
\begin{aligned}
& \vec{R}=-X a_{X}-Y a_{Y}+(F-Z) a_{Z} \\
& |\vec{R}|=\sqrt{X^{2}+Y^{2}+(F-Z)^{2}} \\
& \text { and } \\
& R^{2}=X^{2}+Y^{2}+(F-Z)^{2} \\
& a_{R}=\frac{\vec{R}}{|\vec{R}|}=\frac{-X a_{X}-Y a_{Y}+(F-Z) a_{Z}}{\sqrt{X^{2}+Y^{2}+(F-Z)^{2}}}
\end{aligned}
$$

The equation of a paraboloid is [8]

$$
\frac{X^{2}}{a^{2}}+\frac{Y^{2}}{b^{2}}=\frac{Z}{c}
$$

or

$Z=\frac{c X^{2}}{a^{2}}+\frac{c Y^{2}}{b^{2}}$

Where a,b,c are constants.

$d Q=\rho_{S} d s$, where $\rho_{S}$ is the surface charge density, and $d s=d X d Y$ is a unit area on the paraboloid surface, substitute these relations on the electric field equation (5) gives

$$
d \vec{E}=\frac{\rho_{S} d X d Y}{4 \pi \varepsilon_{0}\left(X^{2}+Y^{2}+(F-Z)^{2}\right.} * \frac{-X a_{X}-Y a_{Y}+(F-Z) a_{z}}{\sqrt{X^{2}+Y^{2}+(F-Z)^{2}}}
$$

If we assume that the $\rho_{S}$ is constant [uniform surface charge i.e. the incident waves distribute uniformly] then the components of electric field on $\mathrm{X}$ and $\mathrm{Y}$ directions will 
vanish and the $\mathrm{Z}$ component will remains only, hence the electric field equation become as follows:

$$
d \vec{E}=\frac{\rho_{S} d X d Y}{4 \pi \varepsilon_{0}} * \frac{(F-Z) a_{z}}{\left(\left(X^{2}+Y^{2}+(F-Z)^{2}\right)^{\frac{3}{2}}\right.}
$$

or

$$
d E_{Z}=\frac{\rho_{S} d X d Y}{4 \pi \varepsilon_{0}} * \frac{(F-Z)}{\left(\left(X^{2}+Y^{2}+(F-Z)^{2}\right)^{\frac{3}{2}}\right.}
$$

If we go back to the equation of the paraboloid

$Z=\frac{c X^{2}}{a^{2}}+\frac{c Y^{2}}{b^{2}}$

For a paraboloid condition, $\mathrm{a}$ and $\mathrm{b}$ must be equal $a=b=\frac{D}{2} \quad$ where $\mathrm{D}$ is the parabolic diameter the constant $\mathrm{c}$ is

$c=\frac{D^{2}}{16 F}$

hence the paraboloid equation becomes :

$Z=\frac{c}{a^{2}}\left(X^{2}+Y^{2}\right)=\frac{1}{4 F}\left(X^{2}+Y^{2}\right)$

Then

$$
d E_{Z}=\frac{\rho_{S}}{4 \pi \varepsilon_{0}} * \frac{\left(F-\frac{1}{4 F}\left(X^{2}+Y^{2}\right)\right) d X d Y}{\left(\left(X^{2}+Y^{2}+\left(F-\frac{1}{4 F}\left(X^{2}+Y^{2}\right)\right)^{2}\right)^{\frac{3}{2}}\right.}
$$

To find the electric field at the focus point, which is on the Z-axis, we must integrate equation(14), the variables $\mathrm{X}$ and $\mathrm{Y}$ will vary from $\frac{-D}{2}$ to $\frac{D}{2}$

$$
E_{Z}=K_{1} \int_{\frac{-D}{2}}^{\frac{D}{2}} \int_{\frac{-D}{2}}^{\frac{D}{2}} \frac{\left(F-\frac{1}{4 F}\left(X^{2}+Y^{2}\right)\right) d X d Y}{\left(\left(X^{2}+Y^{2}+\left(F-\frac{1}{4 F}\left(X^{2}+Y^{2}\right)\right)^{2}\right)^{\frac{3}{2}}\right.}
$$

where $K_{1}=\frac{\rho_{S}}{4 \pi \varepsilon_{0}}$

In this paper we study the effect of (F/D) on electric field and the received power, which is proportional to electric field at the focal point [9]

$S \propto E^{2}$ 


\section{Simulation and Results:-}

Matlab 6.5 code is used to find the numerical integration of electric field equation for different values of antenna diameter and the resultant electric field will be a function of curvature rate (F/D). The same program is used to draw the electric field equation as a function of $(\mathrm{F} / \mathrm{D})$. At the simulation we assume the frequency is constant at $12 \mathrm{GHz}$. The electric field shape is shown in figs (4)-(10) for antenna diameters $0.5 \mathrm{~m}, 1,1.2,1.5,1.8,2$, and $3 \mathrm{~m}$.From the figures we see that the electric field is decrease as (F/D) ratio increases and the electric field increases as (F/D) ratio decreases when the antenna diameter is constant. The electric field is very sensitive to variation in $(\mathrm{F} / \mathrm{D})$ ratio at low level of it, for example when $\mathrm{D}=0.5$ and $(\mathrm{F} / \mathrm{D})=0.1$, the electric field 0.5 (volt per meter), while $(F / D)=0.2$ the electric field will decrease by $3 \mathrm{~dB}$. At high level of $(\mathrm{F} / \mathrm{D})$ ratio, this sensitivity will reduce, for example when $D=0.5$, and $(F / D)=0.25$ the electric field same as $(F / D)=0.3$.If we increase the antenna diameter, the electric field shape will become more stable (no fluctuation) for various values of (F/D) ratio .

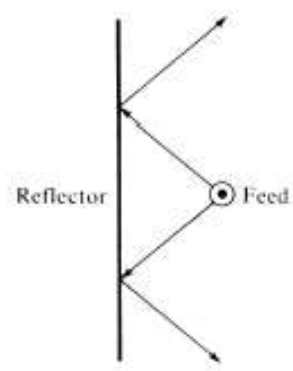

(a) Plane

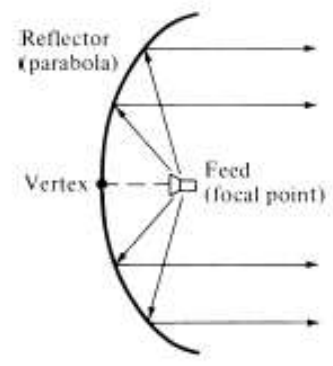

(c) Curved (front-fed)

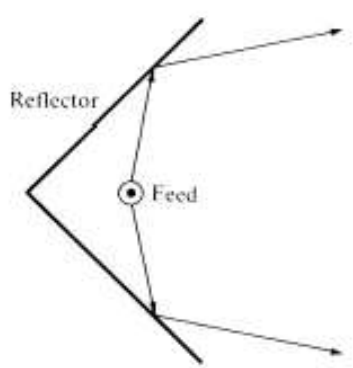

(b) Cornet

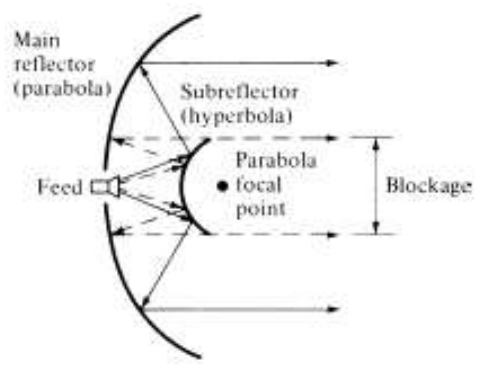

(d) Curved iCassegrain feed)

Fig.(1):Geometrical configuration for reflector systems 

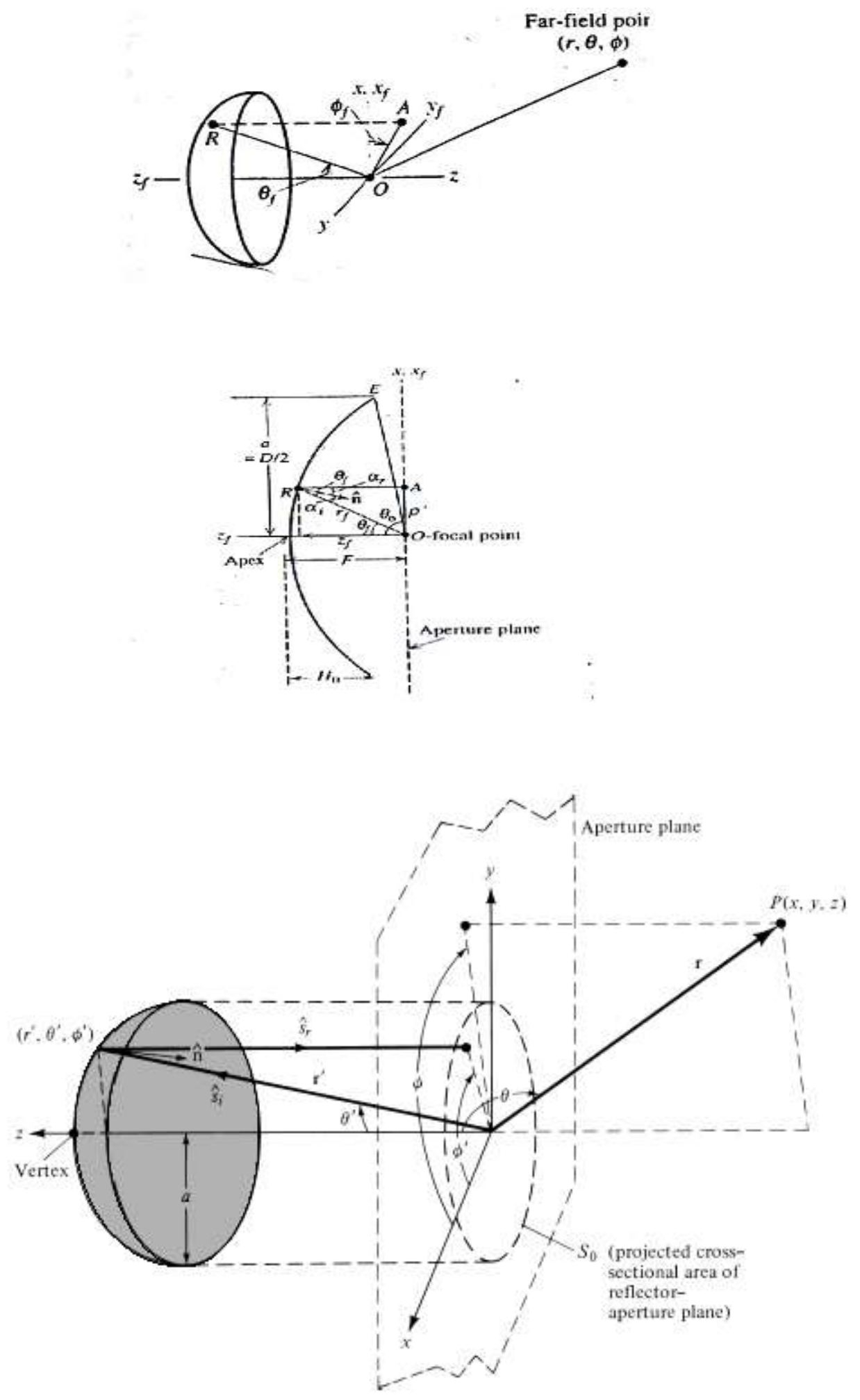

Fig.(2): Three-dimensional geometry of a paraboloidal reflector system 


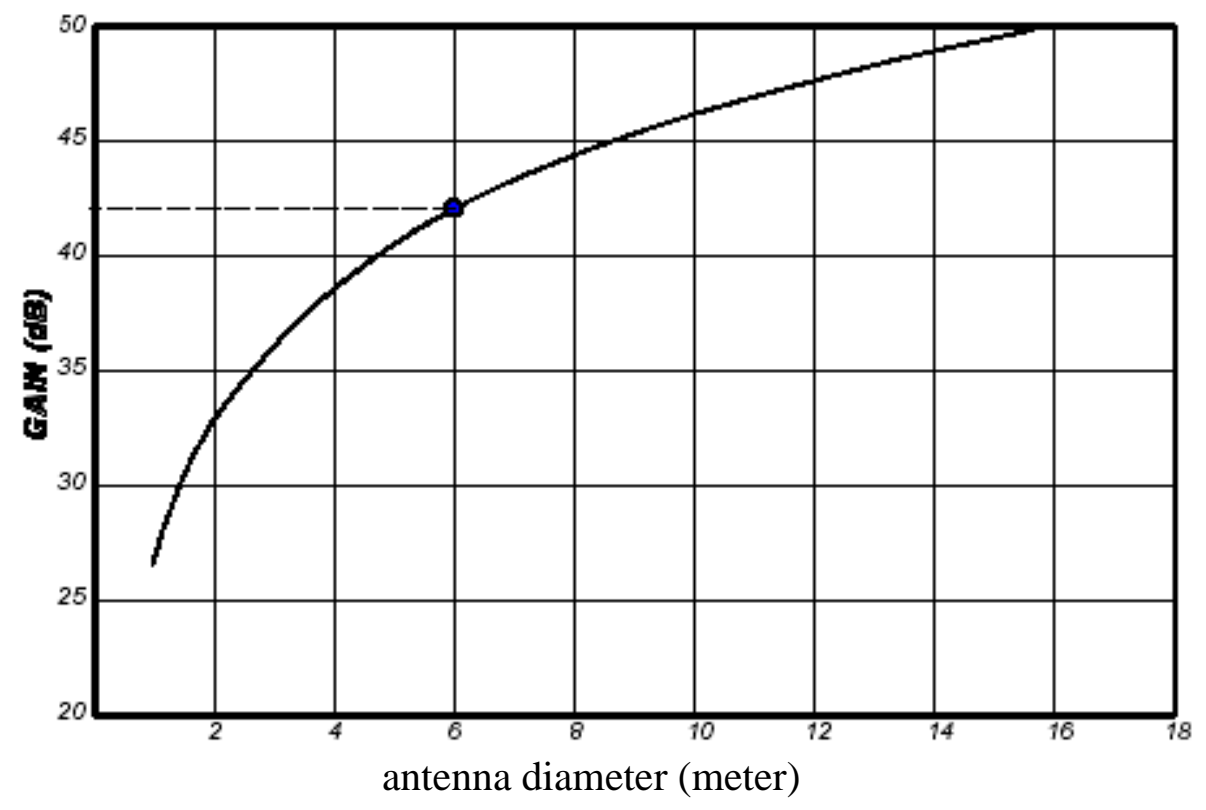

Fig.(3):The antenna gain as a function of diameter

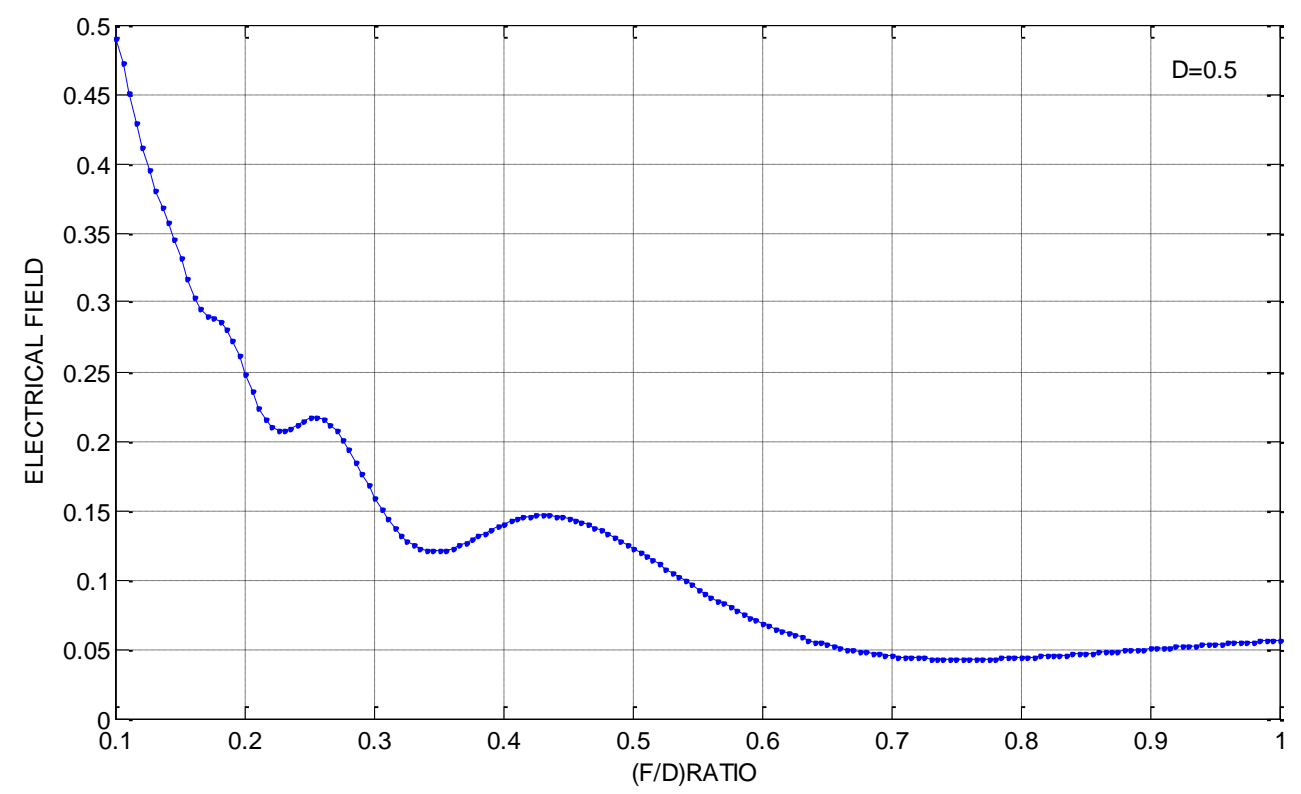

Fig(4): The electric field as a function of $(F / D)$ when $D=0.5 m$ 


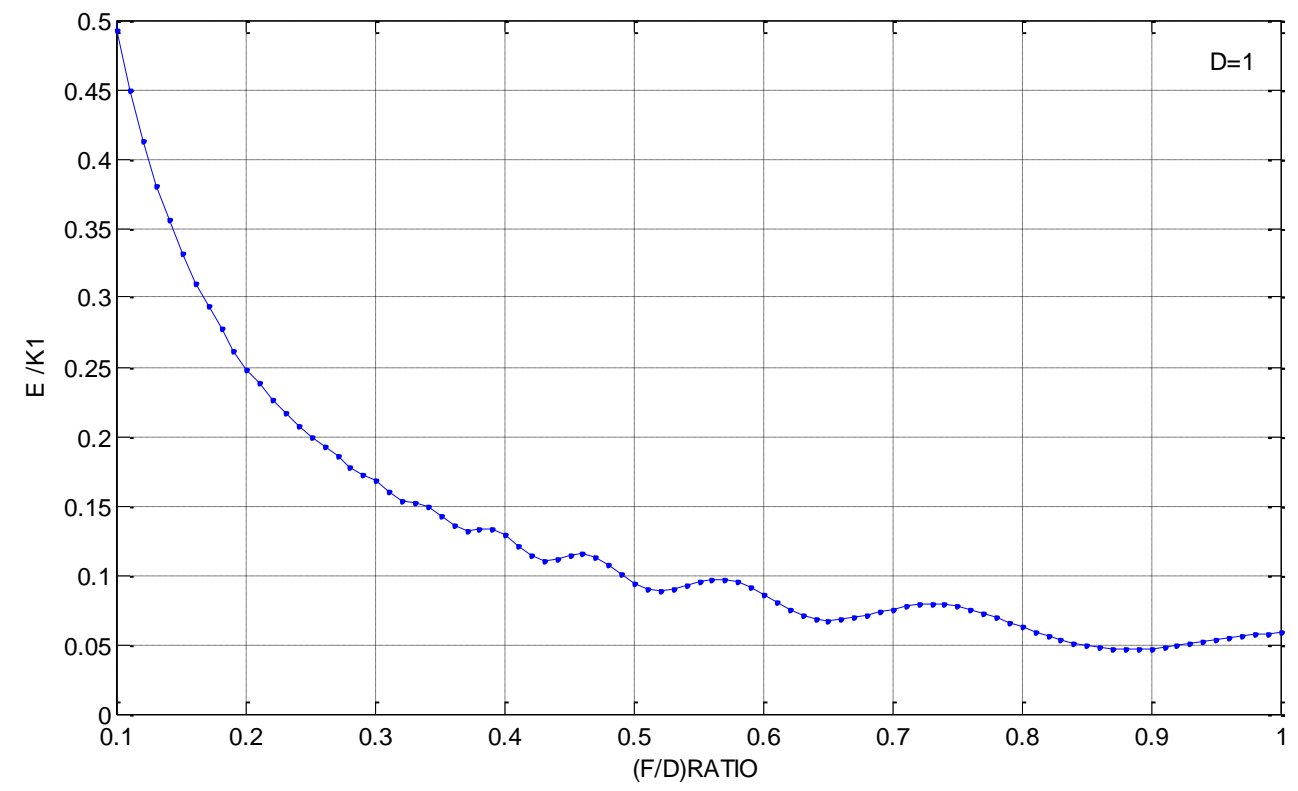

Fig.(5): The electric field as a function of (F/D) when $D=1 \mathrm{~m}$

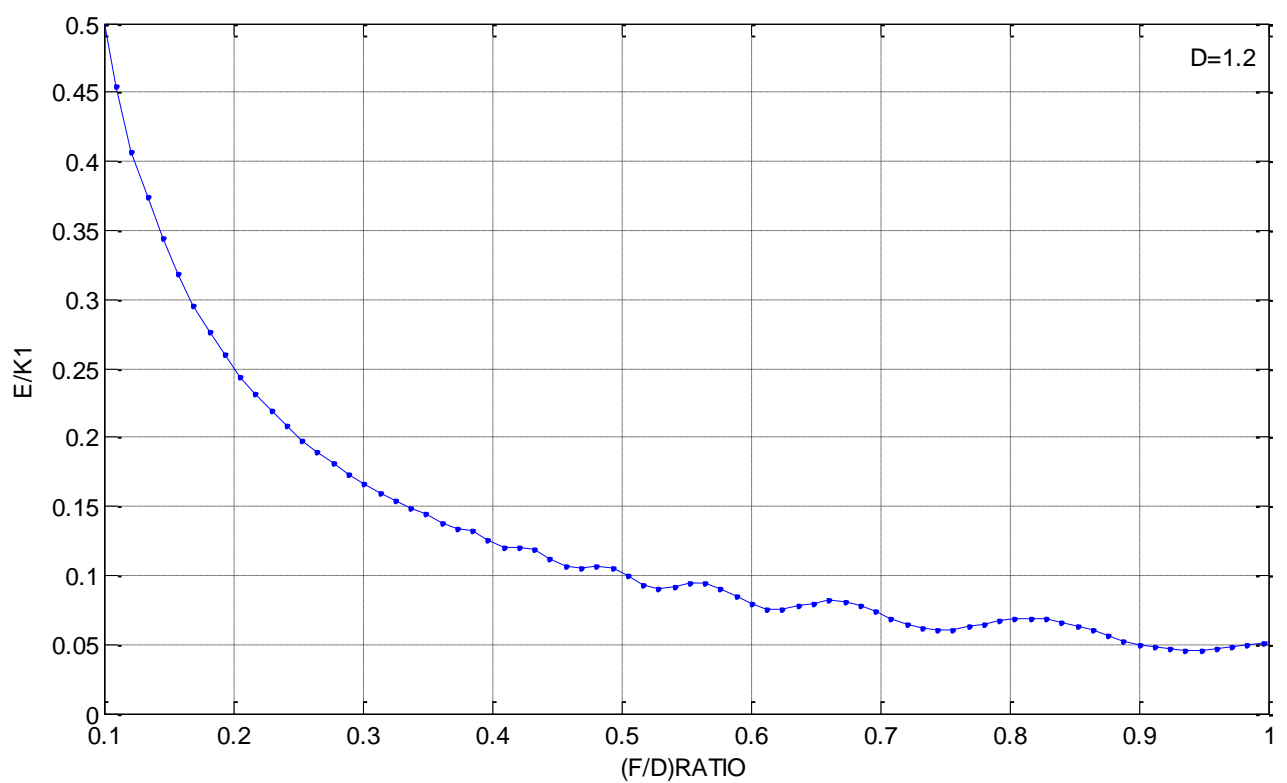

Fig.(6): The electric field as a function of (F/D) when $D=1.2 \mathrm{~m}$. 


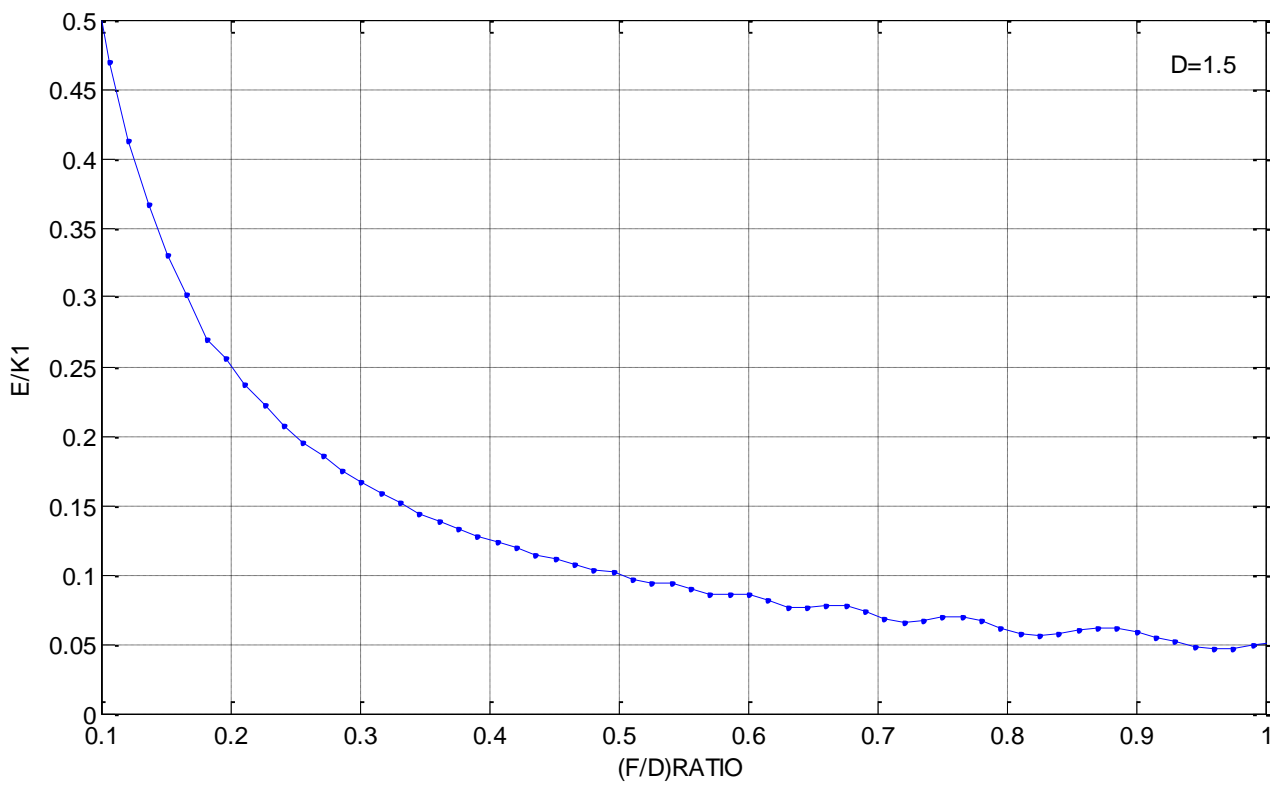

Fig.(7): The electric field as a function of (F/D) when $D=1.5 \mathrm{~m}$.

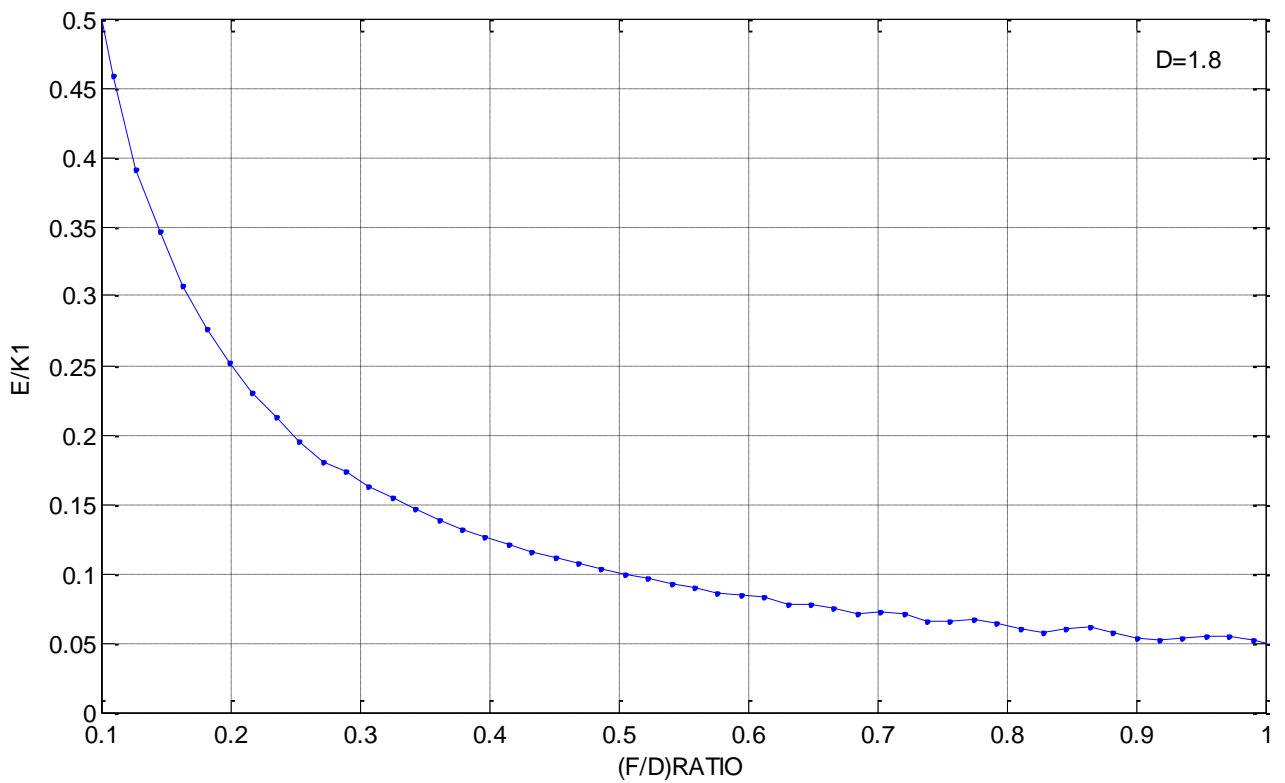

Fig.(8): The electric field as a function of (F/D) when $D=1.8 \mathrm{~m}$. 


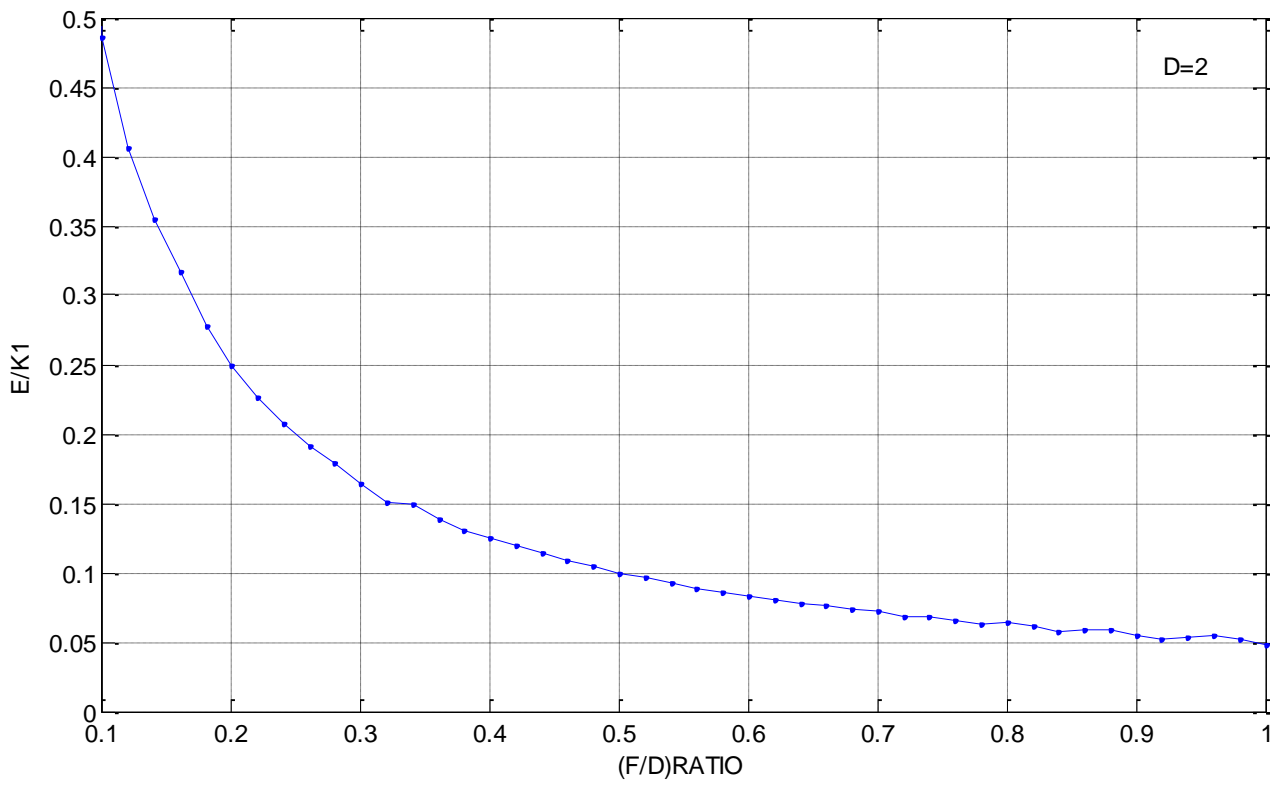

Fig.(9): The electric field as a function of (F/D) when $D=2 \mathrm{~m}$.

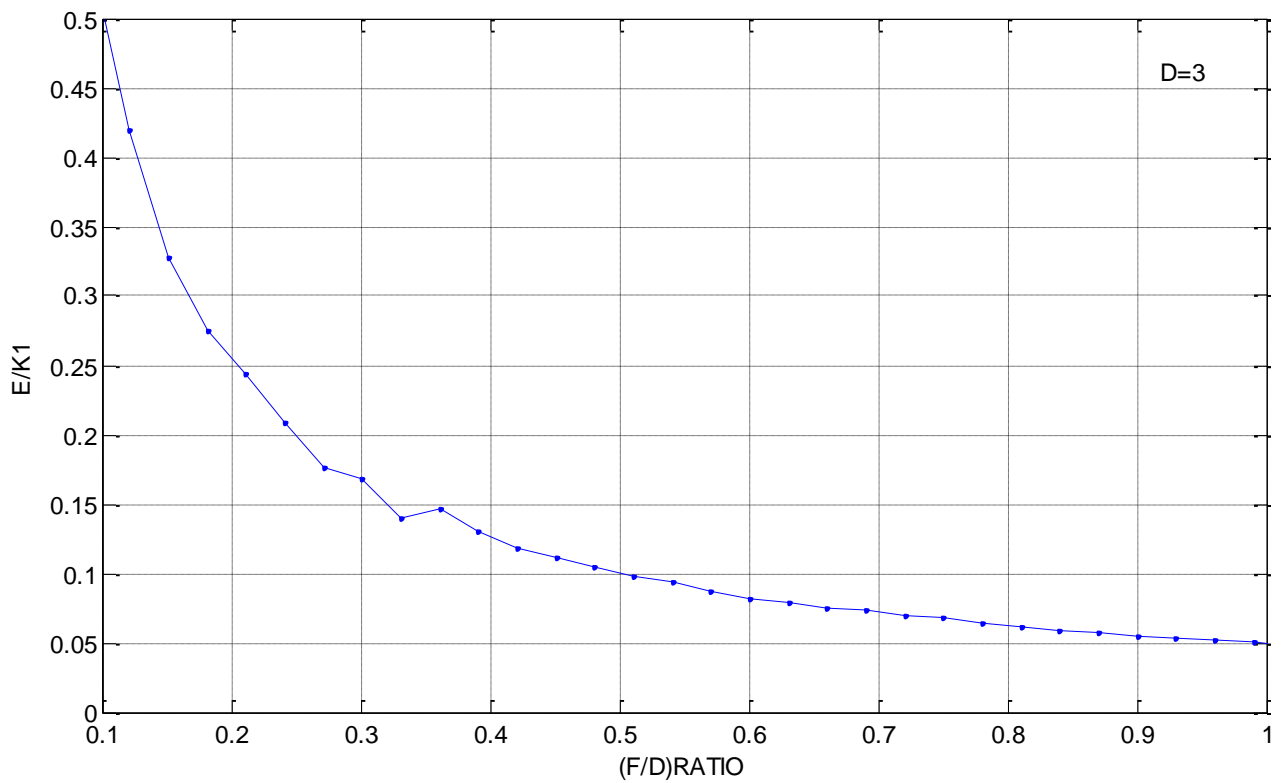

Fig.(10): The electric field as a function of (F/D) when $D=3 m$. 


\title{
References:-
}

[1].C.,A. ,Balanis, Antenna Theory and Design ,John Wily \&Sons, Inc, 2005,pp883 .

[2].A.,W., Love-(ed),' Reflector Antennas", IEEE Press ,New York 1978.

[3].Zhixin Chen, and R.,C., Maher, "Parabolic Dish Microphone System", Montana Stat University,August 12,2005, www.coe.montana.edu/ee/rmaher/publications/maher aac 0805.pdf .

[4].D., Dobricic ," Inverted Amos Antenna as Linear feed for Cylindrical Parabolic Reflector ", AntennaX ,No. 133,May 2008.

[5].W.,L., Stutzman and G.,A., Thiele, Antenna Theory and Design, John Wily \&Sons, Inc, 1998 pp 322-323.

[6]. "Antenna introduction /basics" from www.tsc.com/antennas.pdf

[7].W.,H., Hayt, Engineering Electromagnetic, Sixth Edition, Mc Grow Hill,2005, pp31.

[8].R.,L., Finney and G.,B., Thomas ,Calculus, Addison-Wesley,1978, pp758.

[9].W.,L., Stutzman and G.,A. ,Thiele ,Antenna Theory and Design, John Wily \&Sons ,Inc, 1998, pp 326.

\section{تأثير نسبة الانحناء على القدرة المستلمة في العاكس المكافئ \\ أمين شريف غازي احمد عبد الهادي فاضل \\ كلية الهندسة - جامعة ذي قار}

\begin{abstract}
الخلاصة
تم في هذا البحث دراسة تأثير نسبة الاتحناء على شكل المجال الكهربائي المتولد في نقطة البؤرة عند ثبوت التردد وقطر الهوائي .افترضنا إن الموجات الكهرومغناطيسية تسقط بصورة منساوية على كل نقطة من نقاط

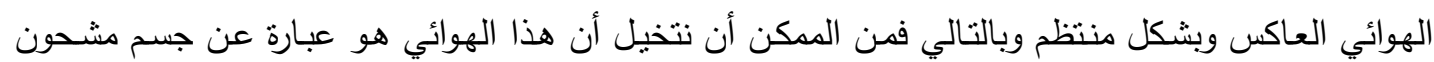
بشحنة سطحية متساوية وهذا الجسم لله القابلية على توليد مجال كهربائي في جميع النقاط المواجهة له (ومن ضمنها نقطة البؤرة) ويمكن حساب هذا المجال باستخدام قانون كولوم .وقد تبين من خلال الاشتقاق أن المجال المتولد سيكون باتجـاه محور التماثل للهوائي ولا تكون هنالك أي مركبة بالاتجاهـات الأخرى .تم رسم هذا المجال المتولد بدلالة نسبة الانحناء ولمختلف قيم قطر الهوائي .وقد أظهرت النتائج أن المجال الكهربائي يزداد كلما قلت نسبة الانحناء ويقل كلما ازدادت نسبة الانحناء عند ثبوت قطر الهوائي .كما أظهرت النتائج أن شكل المجال الكهربائي يكون متذبذبا عندما يكون قطر الهوائي صغيرا ويقل هذا التذبذب كلما ازداد قطر الهوائى عند ثبوت نسبة الانحناء .
\end{abstract}

